\title{
Analytical Based Calculation Approach for Radiated Electromagnetic Energy Absorption Intensity Estimation from Fourth Generation Cellular Radio Networks Base Station Antennas
}

\author{
Igbinovia Anthony Osaigbovo ${ }^{1}$, Joseph Isabona ${ }^{2 *}$ \\ ${ }^{I}$ Department of Physics, College of Education Ekiadolor-Benin, Benin City, Edo State, Nigeria \\ $*^{2}$ Department of Physics, Federal University Lokoja, BPMB 1154, Kogi State, Nigeria
}

*Corresponding Author: Joseph Isabona, Department of Physics, Federal University Lokoja, BPMB 1154, Kogi Sate, Nigeria

\begin{abstract}
Present-day era has been heralded with general public concern about potential health consequence of exposure to radiant electromagnetic waves energy from operational telecommunication base station transceivers. In this work, model-based calculation method is employed to estimate the intensity of exposure and electromagnetic energy absorption level by biological human tissues from specific base station antennas, considering some frequencies of operations of Global System for Mobile Communication (GSM), Universal Mobile Telephone Communication Systems (UMTS) and Long Term Evolution (LTE) in Nigeria. The estimation procedure involves calculating the level of absorption of electromagnetic energy by 11 different human tissues for a variable penetration depth distances from the antennas at $900 \mathrm{MHz}, 1800 \mathrm{MHz}$, $2100 \mathrm{MHz}$ and $2600 \mathrm{MHz}$, respectively. The indicators used as measures for comparative investigation include the electric field strength and Specific absorption rate (SAR).The computed results revealed the LTE antennas at $1800 \mathrm{Mz}$ attained highest SAR level, followed by UMTS 2100MHz antennas, then GSM1800MHz, with $900 \mathrm{MHz}$ being the least. Comparing with recommended ICNIRP limits, which are $2 \mathrm{~W} / \mathrm{kg}$ for general public exposure, the obtained SAR results for all the tissues did not exceed standard except for only blood and kidney that attained $2.2 \mathrm{~W} / \mathrm{kg}$ and $2.1 \mathrm{~W} / \mathrm{kg}$, respectively at LTE $2600 \mathrm{MHz}$.
\end{abstract}

Keywords: Model-based calculation, Radiated electromagnetic energy, Base station antennas, Human tissues, Specific absorption rate, Electric field strength.

\section{INTRODUCTION}

The design, development and introduction of different cellular wireless communication devices such as smart phones, mobile phones, palm tops, etc., have been very rapid and revolutionary in recent time. Apart from calling and test-messaging with the mobile phones, more and more innovative webbased applications like internet banking, email access with alerts/push notifications, mobile television (streaming) and a huge varieties of other distinctive applications can be realize with the phones, especially the smart ones (Isabona, 2013 [1]; WHO, 2010 [2]). Presently, the fourth generation of cellular telecommunication standard known as the Long Term Evolution (LTE) is gradually being introduced worldwide, including Nigeria. This is to enhance the innovative web-based applications of the smart phones in terms of high speed internet service provisioning.

This increasing continuous use and proliferation of cellular mobile phones including other handheld communication devices has in turn steered the increased deployment of base station (BS) antennas everywhere around the populace. This is to provide a robust support for radio signals coverage and good service quality provision to the connected loads (i.e. mobile users). The main concern of these BS antennas and their cellular phone devices is the possible adverse human and public health effect of the amount of electromagnetic (EM) wave radiations that emanate from them, especially at proximity during usage. The exposure to EM waves emanating from BSs is a continuous process, and it irradiates the entire body parts and tissues exposed to them at different levels based on position and separation distance. According to prominent public environmentalists, the EM wave irradiation 
occupies the fourth major pollution source besides air pollution, water pollution and noise pollution in our immediate surroundings.

With the above adverse health hazard concern, there have been considerable number of research investigations exploring different methodology to probe the intensity level of EM radiation from the BS antennas around man in the past 50 years. This includes the use analytical, simulation and field measurements based investigations techniques.

In (Joseph et al., 2006; Sirav \& Seyhan, 2009), the authors studied and revealed the level of EM waves radiation intensity from television and radio transmitters using measurement based techniques. The rate of temperature change in tissues due to radiation exposure to TV transmitters with dipole antenna at high frequency is presented in (Pathak, et al., 2003). In (Kim et al., 2008; Lehmann et a., 2002; Joseph et al., 2006; Neubauer et al., 2002; Olivier \& Martens, 2007) different measurements techniques for assessing the amount of EM radiation in the vicinity of UMTS (Universal Mobile Telecommunications System) and GSM (Global System for Mobile Communications) base stations have been presented. The authors in (Bornkessel et. Al., 2007), provided results of spatial and temporal measurements of radiation levels in GSM, UMTS and WiMAX base stations. Also, the authors in (Kuhn et al., 2014; Myhr, 2004; Verloock et al., 2010; Ojuh \& Isabona, 2015; Isabona \& Odesanya, 2015; Isabona \& Ojuh, 2015) investigated short-period radiation exposure to Wi-Fi access points and GSM base stations, and revealed their compliance level with international recommended guidelines on electromagnetic radiation safety.

In this work, model-based calculation method is employed to estimate the intensity of exposure and electromagnetic energy absorption level by human from specific base station antennas operating at GSM $900 \mathrm{MHz}$, GSM1800MHz, UMTS $2100 \mathrm{MHz}$ and LTE $2600 \mathrm{MHz}$. To the authors' best knowledge, this is the first time a detailed model based calculation and estimation of the intensity of exposure and electromagnetic energy absorption level from antennas on human, covering 11 different human tissues and ranges of frequencies is performed in the location of study.

\section{METHODOLOGY}

\subsection{Theoretical and Model-based Calculation Framework}

In cellular communication systems, radio frequency signals are radiated from the transmitter over the propagation medium to receiver as an electromagnetic wave. Thus, the base station antenna is a special designed electrical device explored for transmitting and receiving electromagnetic waves or energy from its surrounding space in order to create a communication link between two or more mobile phones and related devices.

Maxwell introduced a set of four equations to describe how electromagnetic waves are generated; the equations are (Rapetti \& Rousseaux, 2012):

$$
\begin{aligned}
& \nabla \times E=-\mu \frac{\partial H}{\partial t} \\
& \nabla \times H=\sigma E+\varepsilon \frac{\partial E}{\partial t} \\
& \nabla \times D=\rho \\
& \nabla \times B=0
\end{aligned}
$$

According to equations (1) and (2) above, a time varying electric field generates magnetic field, $H$ and a time varying magnetic generates electric field, $E$ generates magnetic radiates electromagnetic waves (i.e. electric field, $E$ and magnetic fields, $H$ ). When such field exists, power is generated and propagated through a medium. In terms of plane waves, the rate of flow of such electromagnetic wave's power is called power density, S and it can be defined as (Okhuomaruyi \& Okungbowa, 2017):

$$
S=E H
$$

Because, $H=\frac{E}{\eta}$, we can also write equation (1) as: 


$$
S=\frac{E \times E}{\eta}=\frac{E^{2}}{\eta}
$$

Where $\eta$ is the characteristic impedance which expresses the complex ratio of electric field and magnetic field components in the propagation direction.

If a typical base station antenna transmit power, $P_{T}(\mathrm{~W})$ to the receiver networked to its output terminals per square distance meter, the antenna's power density, $\mathrm{S}\left(\mathrm{W} / \mathrm{m}^{2}\right)$ can also be calculated as (Isabona \& Odesanya, 2015; Isabona \& Ojuh, 2015):

$$
S\left(W / m^{2}\right)=\frac{P_{T} G_{T}}{4 \pi d^{2}}
$$

Where $G_{T}$ is the transmitting antenna gain, and d expresses the communication distance with the load (i.e. the receiver). Specifically, Antenna gain, $G_{T}$ articulates the measure of the antenna's capability to direct its input power into a specified radiation direction and is measured at the uttermost radiation intensity.

Combining equations (6) and (7), we have:

$$
S=\frac{E^{2}}{\eta}=\frac{P_{T} G_{T}}{4 \pi d^{2}}
$$

Equation (8) also implies that:

$$
E=\sqrt{\frac{\eta P_{T} G_{T}}{4 \pi d^{2}}}
$$

In free space, $\eta$ can be defined as (Ghasemi et al, 2012, Obahiagbon \& Isabona, 2015):

$$
\eta=\sqrt{\frac{\mu_{0}}{\varepsilon_{0}}}=120 \pi
$$

With $\eta$ expression in equation (10), we can rewrite (9) as:

$$
E=\sqrt{\frac{120 \pi P_{T} G_{T}}{4 \pi d^{2}}}=\frac{\sqrt{30 P_{T} G_{T}}}{d}
$$

In terms of distance, $d$, we have:

$$
d=\sqrt{\frac{30 P_{T} G_{T}}{E}}
$$

\subsection{Penetration Depth of Electromagnetic Energy}

When radiated electromagnetic waves energy comes in contact with a biological body surface, it is reflected, transmitted, refracted or scattered by the biological body. The scattered and reflected fields may perhaps spread to new directions inside or outside the incident radio electromagnetic field. The refracted, transmitted and absorbed fields in turn relate with body cells and tissues fully or partially in diverse capacities, depending on the waveform, frequency, wavelength and power of the induced fields and the electromagnetic energy absorbed or deposited in the body cells and tissues. Penetration depth expresses the extent at which any radiated electromagnetic energy can permeate or penetrate into a body. It can also describe as the depth by which radiation intensity inside the body or material falls to $1 / \mathrm{e}$ (approximately $37 \%$ ) of its original value at the surface.

Electromagnetic energy in term of electric field strength penetrates a body surface boundary by (Kumar et al, 2010): 


$$
E_{P}=E \exp \left(\frac{-d_{p}}{\delta}\right)
$$

where $d_{p}$ indicates the depth of penetration distance, $\delta$ is called the skin depth expressing the distance electromagnetic wave must penetrate a surface before its strength level falloffs by a factor of 1/e, and it is given by (Ghasemi et al, 2012; Kumar et al, 2010):

$$
\delta=\omega\left(\frac{\mu \varepsilon}{2}\left[\left(1+\frac{\sigma^{2}}{\varepsilon^{2} \omega^{2}}\right)^{1 / 2}-1\right]\right)^{1 / 2}
$$

Where

$\omega_{\omega}\{$ \display style lomega $\}=2 \pi f$ (i.e. angular frequency)

$\varepsilon=\varepsilon_{0} \varepsilon_{r}$

$\varepsilon_{0} \mu \mathrm{r}\left\{\right.$ Idisplay style $\left.\backslash \mathrm{mu} \_\{\mathrm{r}\}\right\}=$ permittivity of free space

$\mathcal{E}_{r} \mu \mathrm{r}\left\{\right.$ display style $\left.\backslash \mathrm{mu} \_\{\mathrm{r}\}\right\}=$ relative permittivity of the body

$\mu=\mu_{0} \mu_{r}$

$\varepsilon_{0} \mu \mathrm{r}\left\{\right.$ Idisplay style $\left.\backslash \mathrm{mu} \_\{\mathrm{r}\}\right\}=$ permeability of free space

$\varepsilon_{r} \mu \mathrm{r}\left\{\right.$ \display style $\left.\backslash \mathrm{mu} \_\{\mathrm{r}\}\right\}=$ relative permeability of the body

In quasi-static regime wherein $\omega \varepsilon=\prec \prec \sigma, \delta$ can be approximated $1 / \rho \in$ \{ldisplay style $1 / \mathrm{rho}$ lepsilon\}, as (Rapetti \& Rousseaux, 2014):

$\delta=\sqrt{\frac{2}{\omega \mu \sigma}}=503 \sqrt{\frac{1}{f \sigma}}$

But in the wave regime wherein $\omega \varepsilon=\succ \succ \sigma, \delta$ can be approximated $1 / \rho \in$ \{ldisplay style $1 /$ rho lepsilon\}, as (Rapetti \& Rousseaux, 2012):

$\delta=\frac{2}{\sigma} \sqrt{\frac{\varepsilon}{\mu}}=0.00503 \frac{\sqrt{\varepsilon_{r}}}{\sigma}$

\subsection{Specific Absorption Rate}

Besides electric field strength, power density, magnetic field strength, Specific Absorption Rate (SAR) is another special indicator for assessing the maximum permissible radiation exposure for human. Specifically, SAR expresses the rate of electromagnetic energy deposition per kilogram of human body weight, we (We=mg). Mathematically, SAR can be expressed by Kumar et al, 2010; Obahiagbon \& Isabona, 2015):

$$
S A R=\frac{d}{d t}\left(\frac{d W_{e}}{d m}\right)=\frac{d}{d t}\left(\frac{d W_{e}}{\rho d V}\right)
$$

Where $\mathrm{dm}$ and $\mathrm{dWe}$, indicate the incremental mass and incremental energy cramped by a given volume element, $\mathrm{dV}$ and mass density, $\rho$.

The SAR quantity can be determined from electric strength, mass density, $\rho$ and conductivity of tissue, $\sigma$ by (Igbinovia \& Isabona, 2018):

$S A R=\frac{\sigma E^{2}}{\rho}$ 
Analytical Based Calculation Approach for Radiated Electromagnetic Energy Absorption Intensity Estimation from Fourth Generation Cellular Radio Networks Base Station Antennas

The expression in equation can also be rewritten as:

$$
E=\sqrt{\frac{\rho S A R}{\sigma}}
$$

The SAR quantity is also related to the current density, $J$ in tissue by:

$$
J=(\sigma \rho S A R)^{0.5}
$$

Some of the key dielectric parameters expressed in the above equations and also explored for calculation in this work can be found in table

Table1. Dielectric Properties of the Tissues at Different Frequency (Obahiagbon \& Isabona, 2015; Wessapan Et Al., 2011)

\begin{tabular}{|c|c|c|c|c|c|c|c|c|c|}
\hline & \multicolumn{2}{|c|}{$900 \mathrm{MHz}$} & \multicolumn{2}{c|}{$1800 \mathrm{MHz}$} & \multicolumn{2}{|c|}{$2100 \mathrm{MHz}$} & \multicolumn{2}{|c|}{$2600 \mathrm{MHz}$} & Mass Density \\
\hline & $\varepsilon_{r}$ & $\sigma(S / m$ & $\varepsilon_{r}$ & $\sigma(S / m)$ & $\varepsilon_{r}$ & $\sigma(S / m$ & $\varepsilon_{r}$ & $\sigma(S / m)$ & $\rho\left(k g / \mathrm{m}^{3}\right)$ \\
\hline Blood & 18.93 & 0.38 & 59.37 & 2.04 & 58.85 & 2.26 & 58.01 & 0.86 & 1040 \\
\hline Bone & 12.45 & 0.14 & 11.78 & 0.27 & 11.59 & 0.33 & 11.29 & 0.42 & 1850 \\
\hline Brain & 45.80 & 0.77 & 43.54 & 1.15 & 43.05 & 1.31 & 42.33 & 1.6 & 1040 \\
\hline Fat & 11.33 & 0.11 & 5.34 & 0.08 & 10.92 & 0.22 & 5.26 & 0.11 & 920 \\
\hline $\begin{array}{c}\text { Grey } \\
\text { Matter }\end{array}$ & 52.72 & 0.94 & 50.08 & 1.39 & 49.50 & 1.57 & 48.67 & 1.91 & 1050 \\
\hline Kidney & 58.67 & 1.39 & 54.43 & 1.95 & 53.58 & 2.16 & 52.41 & 2.38 & 1020 \\
\hline Liver & 46.86 & 0.85 & 44.21 & 1.28 & 43.64 & 1.46 & 42.79 & 1.78 & 1040 \\
\hline Muscle & 55.95 & 0.96 & 54.44 & 1.39 & 54.03 & 1.57 & 53.37 & 1.92 & 1480 \\
\hline Skin & 41.40 & 0.87 & 46.39 & 1.82 & 38.43 & 1.31 & 37.85 & 1.54 & 1010 \\
\hline Skull & 16.62 & 0.24 & 15.56 & 0.43 & 15.28 & 0.51 & 14.83 & 0.64 & 1850 \\
\hline $\begin{array}{c}\text { White } \\
\text { Matter }\end{array}$ & 38.88 & 0.59 & 37.01 & 0.91 & 36.58 & 1.05 & 35.99 & 1.29 & 1030 \\
\hline
\end{tabular}

\section{RESUlTS AND ANALYSIS}

This section contains the quantified radiant electromagnetic energy intensity in terms of Electric field strength and specific absorption rate for in each investigated human tissue at GSM $900 \mathrm{MHz}$, GSM1800MHz, UMTS $2100 \mathrm{MHz}$ and LTE $2600 \mathrm{MHz}$ frequencies, using the mathematical models of equations (1) to (20).For the calculation and quantification radiant electromagnetic intensity, the dielectric properties of table 1 are used. The influences of different dielectric properties, operating frequency and penetration depth on SAR and electric field for each human are clearly examined.

The penetration depth of GSM, UMTS and LTE radio electromagnetic energy are calculated using equation (14), the results in table 1 shows how it depends on the tissue dielectric properties and operating frequencies of the communication technologies.

Figures 1 to 8 represent the graphs and values of maximum electric field strength and SAR as a function of penetration distance in tissues. It is observed that both values of electric field strength and SAR decrease when the penetration depth increases, implying the farther the BS antenna is, the lower the intensity of radiation penetration and absorption by the human tissues are.

It is needful to note here that both levels of electric field strength and SAR differ from one tissue to another, owing to variation exist in dielectric parameters of each tissue. From the graphs, field strength and SAR values of the blood are higher, followed by that of the kidney, liver, brain and among others.

More importantly, comparing with recommended ICNIRP limits (Ahlbom et al., 1998), which are10 $\mathrm{W} / \mathrm{kg}$ and $2 \mathrm{~W} / \mathrm{kg}$ for occupational and general public exposure), the obtained SAR results did not exceed standard limits except for blood and kidney tissues that attained $2.2 \mathrm{~W} / \mathrm{kg}$ and $2.1 \mathrm{~W} / \mathrm{kg}$ $2600 \mathrm{MHz}$, respectively. This is due to the higher water contents levels in blood and kidney tissues, compared to others like fat and bone. 
Analytical Based Calculation Approach for Radiated Electromagnetic Energy Absorption Intensity Estimation from Fourth Generation Cellular Radio Networks Base Station Antennas

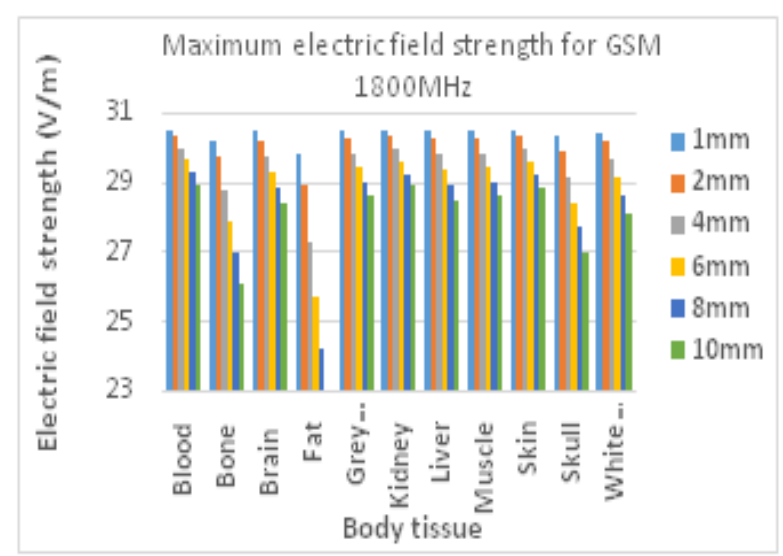

Figure1. Maximum Electric Field Strength at Different Penetration Depth in Human Tissues for GSM $900 \mathrm{MHz}$

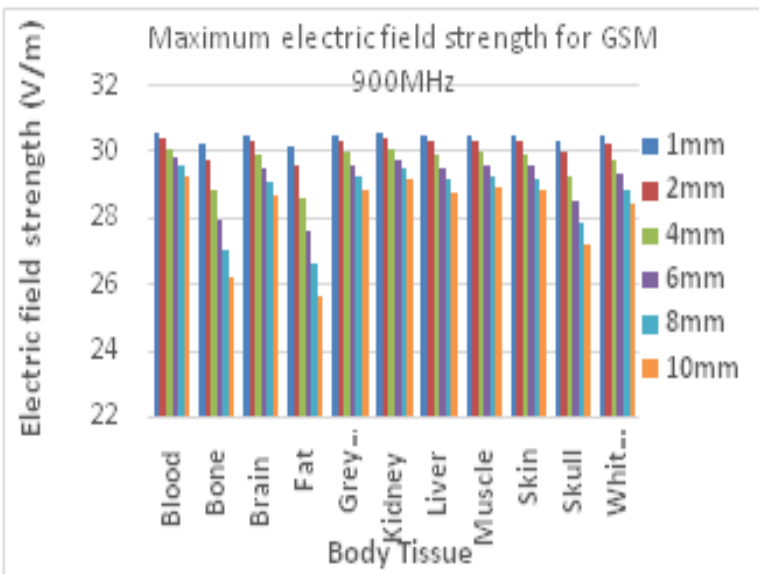

Figure2. Maximum Electric Field Strength at Different Penetration Depth in Human Tissues for GSM $1800 \mathrm{MHz}$

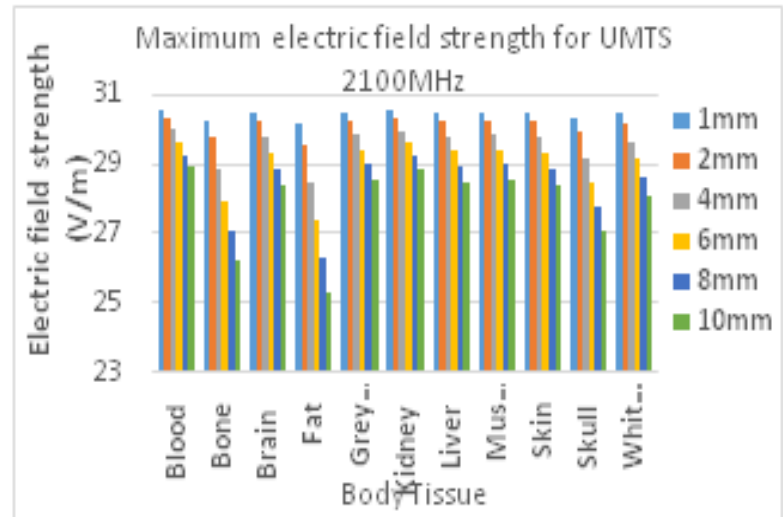

Figure3. Maximum Electric Field Strength at Different Penetration Depth in Human Tissues for UMTS $2100 \mathrm{MHz}$

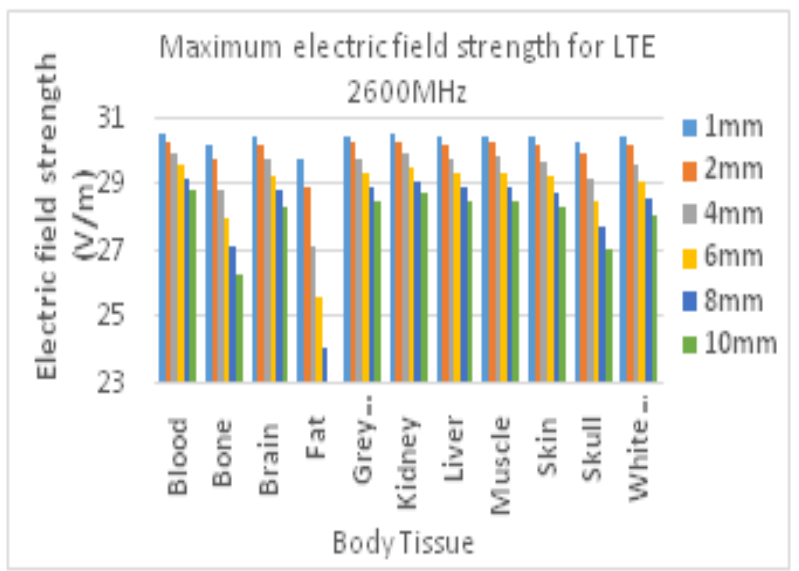

Figure4. Maximum Electric Field Strength at Different Penetration Depth in Human Tissues for LTE $2600 \mathrm{MHz}$ 
Analytical Based Calculation Approach for Radiated Electromagnetic Energy Absorption Intensity Estimation from Fourth Generation Cellular Radio Networks Base Station Antennas

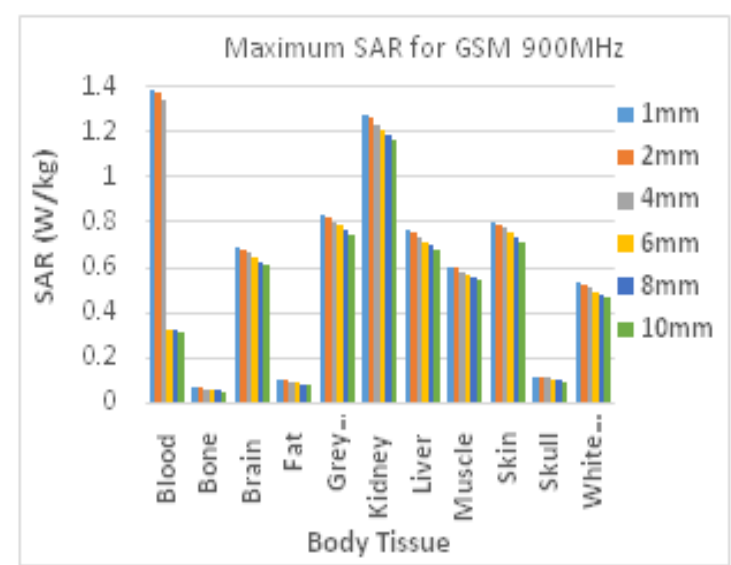

Figure5. Maximum SAR at Different Penetration Depth in Human Tissues for GSM $900 \mathrm{MHz}$

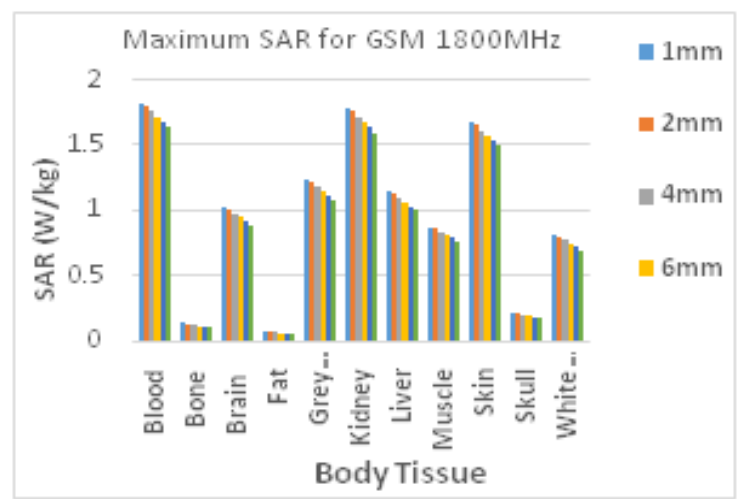

Figure6. Maximum SAR at Different Penetration Depth in Human Tissues for GSM $1800 \mathrm{MHz}$

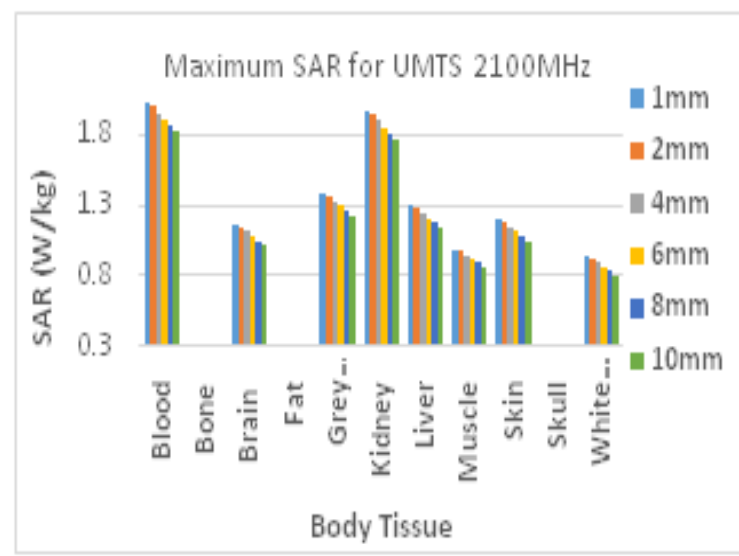

Figure7. Maximum SAR at different penetration depth in human tissues for UMTS $2100 \mathrm{MHz}$

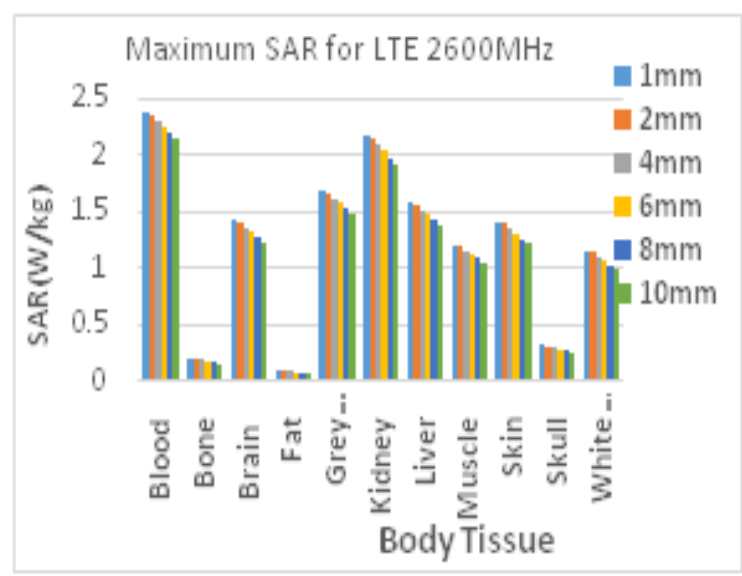

Figure8. Maximum SAR at different penetration depth in human tissues for LTE $2600 \mathrm{MHz}$ 
Figure 9 is plotted to examine the impact of BS antenna transmitting frequency on their intensity electromagnetic energy absorption. In terms of SAR values, figure 9shows that electromagnetic energy absorption at lower frequencies are lesser, compared to higher ones. This is due to longer wavelength with lower frequencies compared to higher ones. In figure 10, the reverse is the case for electric field values and it indicates that higher frequencies produce higher radiation intensity. This is because SAR level is highly influenced by the dielectric properties of the tissues which increases with increasing frequency. This implies that the higher the operating frequency an antenna is, the more human tissues with higher dielectric properties will absorb radiant electromagnetic energy form the antenna. It is clearly evident from figures 9 and 10 that highest SAR and electric field strength values are displayed by blood, kidney, liver and brain tissues, owing their higher water content compared to fat and bone with lower water contents. Comparing with recommended ICNIRP limits ((ICNIRP, 1998), which is $10 \mathrm{~W} / \mathrm{kg}$ (occupational exposure) and $2 \mathrm{~W} / \mathrm{kg}$ (general public exposure)the obtained SAR results for all the tissues did not exceed standard except for only blood and kidney that attained $2.2 \mathrm{~W} / \mathrm{kg}$ and $2.1 \mathrm{~W} / \mathrm{kg}$ at LTE $2600 \mathrm{MHz}$, respectively. This Field strength and SAR values other investigated tissues can be found in tables 2 to 10 .

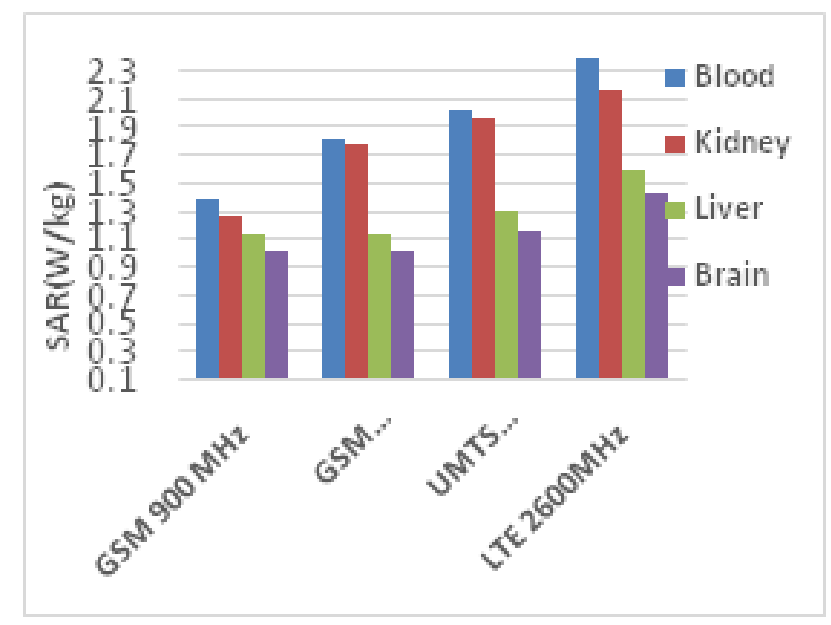

Figure9. Maximum Electric Field Strength in Tissues for Different Telecom Standard and Their Operating Frequencies

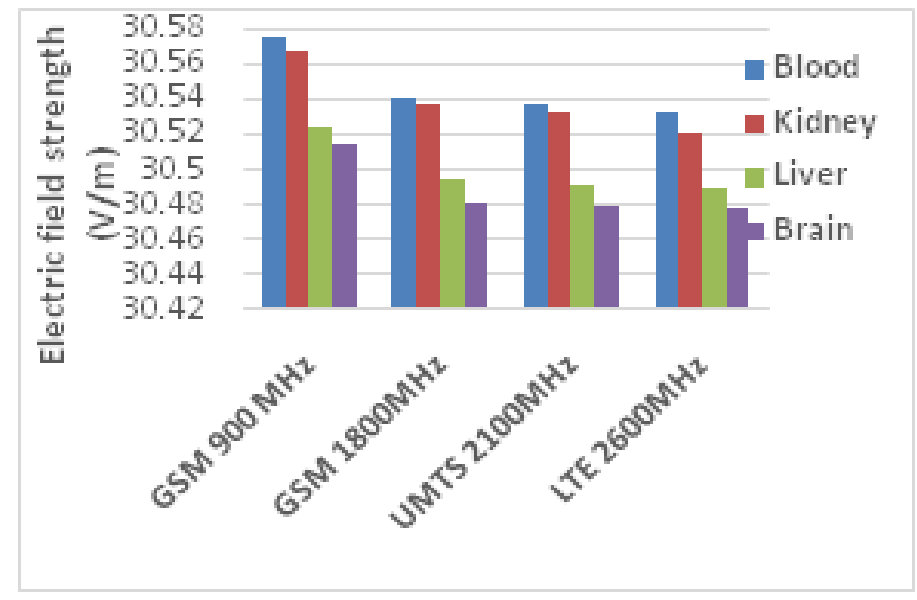

Figure10. Maximum SAR in Tissues for different Telecom Standard and their operating Frequencies

\section{CONCLUSION}

The evolution and deployment of different cellular wireless communication technologies such as smart phones, mobile phones, palm tops, etc. and their supporting base station transceivers, has been very rapid in recent time. On the other hand, general public concern about potential health consequence of exposure to radiant electromagnetic waves energy from operational telecommunication base station transceivers has also been enormous in most recent time. In this work, modeling-based calculation method has been presented to determine the intensity of exposure and electromagnetic energy absorption level by human from base station antennas operating at GSM 
900MHz, GSM1800MHz, UMTS $2100 \mathrm{MHz}$ and LTE $2600 \mathrm{MHz}$ respectively. The computed results revealed the LTE antennas at $1800 \mathrm{Mz}$ attained highest SAR level, followed by UMTS $2100 \mathrm{MHz}$ antennas, then GSM $1800 \mathrm{MHz}$, with $900 \mathrm{MHz}$ being the least. Comparing with recommended ICNIRP limits, which are $2 \mathrm{~W} / \mathrm{kg}$ for general public exposure, the obtained SAR results for all the tissues did not exceed standard except for only blood and kidney that attained $2.2 \mathrm{~W} / \mathrm{kg}$ and $2.1 \mathrm{~W} / \mathrm{kg}$, respectively at LTE $2600 \mathrm{MHz}$.

It will be better, if the obtained results of the model-based calculation method employed in this work to estimate the intensity of exposure and electromagnetic energy absorption level by biological human tissues is complemented with detailed experimental works. This is however slated for our future study.

\section{REFERENCES}

[1] Ahlbom, A., Bergqvist, U., Bernhardt, J. H., Cesarini, J. P., Court, L. A., Grandolfo, M., Hietanen, M., McKinlay, A. F., Repacholi, M. H., Sliney, D. H., Stolwijk, J., Swicord, M.L., Szabo, L. D., Taki, M., Tenforde, T. S., Jammet, H. P. \& Matthes, R. (1998). Guidelines for Limiting Exposure to time-varying Electric, Magnetic, and Electromagnetic fields (up to $300 \mathrm{GHz}$ ), Health Physics, 74 (4), 1998.

[2] Bornkessel C, Schubert M, Wuschek M, Schmidt P. (2007). Determination of the general public exposure around GSM and UMTS base stations. Radiat Prot Dosimetry, 124, 40-47.

[3] Ghasemi, A., Abedi, A \& Ghasemi, F. (2012). Basic Principles in Radio wave Propagation, Propagation Engineering in Wireless Communications, ( $)$ Springer Science + Business Media, 23-54

[4] Igbinovia A.O and Isabona, J. (2018). Current Density and SAR Analysis of Biological Tissues due to Radiant Electromagnetic Waves from Base Station Antennas. Advanced Research in Physical Science (IJARPS), 5 (1), 15-23.

[5] Isabona Joseph (2013). Harnessing Telecommunications Revolution in Nigeria: A Case Study." Wireless and Mobile Technologies, 1(1), 20-24.

[6] Isabona, J and Odesanya, I. (2015). Quantitative Estimation of Electromagnetic Radiation Exposure in the Vicinity of Base Transceiver Stations via in-situ Measurements Approach, Journal of Applied Science and Research, 3 (2), 28-40.

[7] Isabona, J and. Ojuh, O. D (2015). Experimental Assessment of Specific Absorption Rate Using Measured Electric Field Strength in Benson Idahosa University and Environs. American Journal of Modern Physics. 4, (2), 92-96.

[8] Joseph W, Vermeeren G, Verloock L, Heredia MM, Martens L. (2008). Characterization of personal RF electromagnetic field exposure and actual absorption for the general public. Health Phys., 95(3), 317-30.

[9] Joseph W, Verloock L, (2006). Martens L. Reconstruction of the Polarization Ellipse of the EM fieldof Base Station Antennas by a Fast and Low-cost Measurement Method. IEEE Trans. Electromag. Compat, 48(2), $385-396$.

[10] Kuhn S, Lott U, Kramer A, Kuster N. (2007). Assessment Methods for Demonstrating Compliance With Safety Limits of Wireless Devices Used in Home and Office Environments. IEEE Trans. Electromag. Compat. 49(3), 519-525.

[11] Kumar, V. Vats, R.P and Pathak, P.P. (2008). Harmful effects of 41 and $202 \mathrm{MHz}$ radiations on some body parts and tissues", Indian Journal of Biochemistry \& Biophysics, 45, 269-274.

[12] Kim, B.C, Choi H-D, Park S-O (2008). Methods of evaluating human exposure to electromagnetic fields radiated from operating base stations in Korea. Bioelectromagnetics 29(7):579-582; 2008.

[13] Kumar, V., Ahmad, M \& Sharma, A. K. (2010). Harmful effects of Mobile Phone Waves on Blood Tissues of the Human Body, Eastern Journal of Medicine, 15, 80-89.

[14] Lehmann H, Fritschi P, Eicher B. (2002). Indoor measurements of the electrical field close to mobile phone base stations. Proceedings of 27th triennial General Assembly of the International Union of Radio Science, Maastricht, The Netherlands, 1-31.

[15] Myhr J (2004). Measurement method for the exposure to electromagnetic field strength from WLANsystems. Master thesis, Chalmers University of Technology, Goteborg, Sweden; 2004.

[16] Neubauer G, Giczi W, Schmid G. (2002). An optimized method to determine exposure due to GSM base stations applied in the city of Salzburg. Proceedings of the Annual Meeting of the Bioelectromagnetics Society, Quebec, Canada, BEMS: 46-47; 2002.

[17] Obahiagbon, K \& Isabona, J (2015). Specific Absorption Rate and Temperature rise Computation in Human Tissues due to Electromagnetic Field Emission from Mobile Phones at $900 \mathrm{MHz}$ and $1800 \mathrm{MHz}$, Computing, Information Systems, Development Informatics and Allied Research Journal, 6, (2), 53-61.

International Journal of Research Studies in Electrical and Electronics Engineering (IJRSEEE) Page | 16 
Analytical Based Calculation Approach for Radiated Electromagnetic Energy Absorption Intensity Estimation from Fourth Generation Cellular Radio Networks Base Station Antennas

[18] Ojuh, O. D, and J. Isabona, (2015). Radio Frequency EMF Exposure due to GSM Mobile Phone Base Stations: Measurement and Analysis in Nigerian Environment, Nigerian Journal of Technology, 34 (4), 809-814.

[19] Olivier C and Martens L. (2007). Optimal settings for frequency-selective measurements used for the exposure assessment around UMTS base stations. IEEE Trans. on Instr. Meas. 56 (5), 1901-1909.

[20] Okhuomaruyi D. O \& Okungbowa. G.E (2017). Evaluation of Specific Absorption Rate Distributions from GSM Base Stations in Benin City, Nigeria. International Journal ofChemical and Biomedical Science, 3 (3), 2017, 18-25.

[21] Pathak, P.P. Kumar V. \& Vats, R.P. (2003). "Harmful Electromagnetic Environment near Transmission Tower, Indian J. Radio Space Phys. 32, 238-241.

[22] Sirav, B and Seyhan, N. (2009). Radio Frequency Radiation (RFR) from TV and Radio Transmitters at a Pilot Region in Turkey", RadiatProtDosimetry, 136 (2), 114-117.

[23] Rapetti, F \& Rousseaux, G (2012). On quasi-static models hidden in Maxwell's equations, Applied Numerical Mathematics, 79, 97-106.

[24] Verloock L, Joseph W, Vermeeren G, and Martens L. (2010). Procedure for assessment of general public exposure from WLAN in offices and in wireless sensor network testbed. Health Physics 98(4), 628-638.

[25] Wessapan, T., Srisawatdhisukul, S \& Rattanadecho, P. (2011). The effects of dielectric shield on specific absorption rate and heat transfer in the human body exposed to leakage microwave energy, International Communications in Heat and Mass Transfer, 38, 255-262.

[26] WHO (2010).World Health Organization (WHO) Research Agenda for Radiofrequency

[27] Fields. Geneva. 2010. whqlibdoc.who.int/publications/2010/9789241599948_eng.pdf

[28] Wout Joseh W, Leen Verloock and Luc Martens (2006). Reconstruction of the Polarization Ellipse of the EM Field of Telecommunication and Broadcast Antennas by a Fast and Low-Cost Measurement Method", IEEE Trans Electromagn. Compat, 48 (2), 385-396, 2006.

Citation: Igbinovia Anthony Osaigbovo \& Joseph Isabona "Analytical Based Calculation Approach for Radiated Electromagnetic Energy Absorption Intensity Estimation from Fourth Generation Cellular Radio Networks Base Station Antennas", International Journal of Research Studies in Electrical and Electronics Engineering, 5(1), pp 8-17. http://dx.doi. org/10.20431/2454-9436.0501002

Copyright: (C) 2018 Authors. This is an open-access article distributed under the terms of the Creative Commons Attribution License, which permits unrestricted use, distribution, and reproduction in any medium, provided the original author and source are credited. 